\title{
Price and volume relationships across water trading zones
}

\author{
R. Brooks \& E. Harris \\ Monash University, Australia
}

\begin{abstract}
In the Australian context greater policy reliance has been placed on the role that market based solutions can play in solving problems in the allocation of irrigation water. In Northern Victoria one of the most active areas of water trading is in the Goulburn-Murray Irrigation District. To facilitate water trading in this area an electronic market clearing mechanism exists through the Watermove arrangements. Under the Watermove arrangements the state is divided into regions and trading zones, however most of the trading zones have very little trading activity. This paper explores relationships in price and volumes across the two most active trading zones in the Goulburn-Murray Irrigation District in Northern Victoria. While previous papers have explored spatial dimensions of pricing across trading zones our focus is on relationships driven by price and volume characteristics. An analysis of price and volume relationships across trading zones enables an understanding of whether trading volume in a zone produces more informed prices and enables that zone to take on a price leadership role. Our analysis considers the stationarity properties of the price and volume data across the two trading zones and then estimates VAR models of the price and volume relationships across these trading zones. From the VAR models we are able to conduct both Granger causality tests and variance decomposition analysis. This analysis shows that the most actively traded of the two trading zones (the Greater Goulburn trading zone) plays the key role in price leadership. This finding is broadly consistent with previous research on highly liquid financial markets and suggests that irrigation water markets are developing characteristics similar to more liquid financial markets, giving confidence in their successful operations.
\end{abstract}

Keywords: water markets, price leadership, Australia, Murray-Darling basin. 


\section{Introduction}

In recent years Australia like many other countries has explored the feasibility of adopting market based solutions to combat rising environmental problems including irrigation water and greenhouse gas emissions. In the area of irrigation water Harris [1] details the switch in approach from government institutions to markets and how historical path dependencies have impacted current outcomes. The impacts of trading restrictions derived from historical arrangements are also explored in Brennan [2,3]. Despite these trading restrictions existing water markets have been found to produce significant gains in Brennan [2] and Brooks and Harris [4]. For the markets in Victoria an electronic clearing house arrangement is provided by Watermove. The Watermove arrangements reflect the division of the state into regions and trading zones that reflect the institutional arrangements and structures around water trading. As discussed in Brennan [2] the overwhelming majority of the trade is in temporary water rights. In addition, the bulk of the trading is the Northern Victoria Regulated region and focused in three trading zones. Thus, the analysis of the operation of markets for irrigation water has focused on either all three of these trading zones (see Brooks and Harris [4]) or only the most active trading zone, the Greater Goulburn (see Wheeler et al. [5]).

An interesting issue is the extent to which the actively traded zones provide a more general leadership role in the setting of prices. Bjornlund [6] identifies that the market exchanges provide information in price setting to both traders and brokers that conduct private trades. Brennan [2] also shows the spatial relationships between prices across the trading zones. Our focus is on the issue of whether it is possible to identify price leadership across the trading zones based on market activity and trading volume.

The idea that larger and more active trading activity has a more active role in price setting has been explored in a number of areas of empirical finance. In the context of price discovery in foreign exchange markets Menkhoff and Schmeling [7] explore which traders convey the most information to market prices. They find that trader size is one of the factors that impacts information flow and large traders provide more information. At an aggregate market level the relationship has been explored across futures and spot markets. In the analysis of price discovery for Taiwanese stock indices Roope and Zurbruegg [8] find that the more active Singapore futures market for Taiwanese stock indices plays a larger role than the local and less active Taiwanese futures market, although both markets are still influential. In a follow up study Hsieh [9] shows that reforms to reduce transaction costs in Taiwan and thus increase volumes have reduced the information advantage of the Singapore market. In the context of stock markets Chordia and Swaminathan [10] find that the returns of high volume stocks lead the returns of low volume stocks, a finding they attribute to informational advantages derived in part from trading volume.

The focus of the present paper is to examine if the price leadership findings for financial markets extend across to water markets. In previous research Brooks et al. [11, 12] have found that market depth and price clustering 
characteristics common in financial markets are also present in newly developed water markets. Thus, we explore whether a similar finding applies to price leadership characteristics. This is potentially informative as to the efficiency of water markets.

\section{Data and results}

We collected data on weekly prices and volume (megalitres) traded for the water allocation pool exchange for the Greater Goulburn and the Victorian Murray (Barmah to SA) trading zones in the Northern Victoria Regulated region for the period from August 2007 to June 2010 from the Watermove website (www.watermove.com.au). There is one week in this period for which there were no trades in the Greater Goulburn trading zone and five weeks for which there were no trades in the Victorian Murray (Barmah to SA) trading zone. For these weeks we record the volume traded at zero and calculate a market price as the average of the highest buy offer and the lowest sell offer (where there is no buy or sell offer we record that offer price as zero). For all other trading zones there are too many trading weeks for which market prices would need to be imputed for these zones to be included in the analysis. The descriptive statistics for the data are shown in table 1 . We also compared the summary statistics to those for the weeks in which there were actual trades. This comparison shows that the use of our calculated/imputed market prices for a small number of weeks does not impact the calculated summary statistics. The results also show that the summary statistics for prices do not vary much across the two trading zones. In contrast, the volume data shows significant variation across the two trading zones. The volumes in the Greater Goulburn trading zone are much larger. In addition the volumes in the Victorian Murray (Barmah to SA) trading zone are much more leptokurtic, this is due to a small number of large trading volume weeks for this trading zone.

Table 1: $\quad$ Summary statistics for price and volume data by trading zone.

\begin{tabular}{|l|l|l|l|l|}
\hline & \multicolumn{2}{|c|}{ Greater Goulburn } & \multicolumn{2}{l|}{ Vic. Murray (Barmah to SA) } \\
\hline & Price & Volume & Price & Volume \\
\hline Mean & 378.91 & 1129.40 & 377.47 & 168.04 \\
\hline Median & 326.20 & 1146.50 & 323.75 & 117.00 \\
\hline Std Deviation & 235.43 & 673.07 & 241.68 & 156.20 \\
\hline Skewness & 1.078 & 0.040 & 1.140 & 1.772 \\
\hline Kurtosis & 3.676 & 1.948 & 3.806 & 8.269 \\
\hline
\end{tabular}

The previous research on price leadership in financial markets has typically been conducted in a co-integration vector error correction model (VECM) framework for prices (for details see Roope and Zurbruegg [8], Hsieh [9]) or in a VAR framework for returns (for details see Chordia and Swaminathan [10]). For studies of foreign exchange and stock markets the efficient markets and/or random walk hypothesis can be reasonably expected to work given the relatively 
continuous trading frequency. Trading in water markets is much less continuous with only a weekly electronic exchange. Thus, we first need to explore the stationarity of the data in water markets to determine if we need to estimate a VAR or VECM model to explore the relationships between the price and volume variables across the two trading zones. To analyse the stationarity properties of the data we apply unit root tests at both the group and individual series level. Application of unit root tests at both the group level (see Levin et al. [13]) and at the individual series level show that the series are stationary and thus our analysis proceeds with a standard VAR model in levels. A key issue in the application of a VAR model is the choice of lag length in the model specification. There are a number of possible approaches that can be adopted here, including sequential likelihood ratio tests (LR), final prediction error criterion (FPE) and a range of model selection criteria (Akiake (AIC), Schwarz (SC), Hannan-Quinn (HQ)). For maximum lag lengths from 3 to 8 the individual criteria make the same choice across the different lag lengths, specifically $\mathrm{LR}=3, \mathrm{FPE} \& \mathrm{AIC}=2, \mathrm{SC} \& \mathrm{HQ}=1$. For longer maximum lengths the choice of all of the methods remains the same, except for the LR tests that now make a choice of 7. In our analysis we consider a VAR models with a lag specification of 2 .

In our analysis we are interested in the influence of volume on price (and vice versa) within the one trading zone and across trading zones. We explore this influence in two ways: first, via Granger causality tests of the significance of the lagged variables; and second, via variance decomposition analysis. The results of our Granger causality tests are reported in table 2, while the results of the variance decomposition analysis are reported in table 3 . The Granger causality test results report the value of the $\chi^{2}$ test statistic and its associated $p$-value. The results show a limited set of significant lag terms. There are significant spillovers between prices across the two trading zones in both directions. The bidirectional information flows between both series are consistent with the findings of Roope and Zurbruegg [9]. In addition Greater Goulburn prices impact Greater Goulburn volumes, and Greater Goulburn volumes also impact Victorian Murray (Barmah to SA) volumes.

Table 2: $\quad$ Granger causality tests of lagged terms.

\begin{tabular}{|l|l|l|l|l|}
\hline & \multicolumn{2}{|c|}{ Greater Goulburn } & \multicolumn{2}{c|}{ Vic. Murray (Barmah to SA) } \\
\hline Lags of & Price & Volume & Price & Volume \\
\hline Grt. Goulburn & & 9.624 & 52.325 & 0.214 \\
Price & & $(0.008)$ & $(0.000)$ & $(0.899)$ \\
\hline Grt. Goulburn & 2.299 & & 0.965 & 7.835 \\
Volume & $(0.316)$ & & $(0.617)$ & $(0.020)$ \\
\hline Vic. Murray & 6.507 & 4.362 & & 0.567 \\
Price & $(0.039)$ & $(0.113)$ & & $(0.753)$ \\
\hline Vic. Murray & 2.737 & 2.410 & 1.600 & \\
Volume & $(0.254)$ & $(0.300)$ & $(0.449)$ & \\
\hline
\end{tabular}


The variance decomposition analysis reports the percentage share of the variance to 4 lags. The results show that for the Greater Goulburn trading zone that own variable impacts dominate the variance decomposition. In contrast for the Victorian Murray (Barmah to SA) trading zone the Greater Goulburn variables also play a significant role. For volume in the Victorian Murray (Barmah to SA) trading zone own volume plays the dominant role with a strong impact also for Greater Goulburn trading zone volume. For prices it is Greater Goulburn trading zone prices that dominate the variance decomposition for the Victorian Murray (Barmah to SA) trading zone prices. This demonstrates the dominant price leadership role played by the prices in the more actively traded Greater Goulburn trading zone. These findings are again broadly consistent with those reported in Roope and Zurbruegg [8].

Table 3: $\quad$ Variance decomposition analysis.

\begin{tabular}{|l|l|l|l|l|}
\hline & \multicolumn{2}{|c|}{ Greater Goulburn } & \multicolumn{2}{l|}{ Vic. Murray (Barmah to SA) } \\
\hline $\begin{array}{l}\text { Share of } \\
\text { Variance }\end{array}$ & Price & Volume & Price & Volume \\
\hline $\begin{array}{l}\text { Grt. Goulburn } \\
\text { Price }\end{array}$ & 94.35 & 3.77 & 82.01 & 1.24 \\
\hline $\begin{array}{l}\text { Grt. Goulburn } \\
\text { Volume }\end{array}$ & 0.81 & 93.93 & 0.79 & 22.32 \\
\hline $\begin{array}{l}\text { Vic. Murray } \\
\text { Price }\end{array}$ & 2.94 & 1.20 & 15.59 & 0.11 \\
\hline $\begin{array}{l}\text { Vic. Murray } \\
\text { Volume }\end{array}$ & 1.90 & 1.10 & 1.61 & 76.33 \\
\hline
\end{tabular}

\section{Conclusion}

This paper has explored the price and volume relationships across the two most active trading zones for irrigation water in the Goulburn-Murray Irrigation District. Consistent with the available evidence for financial markets we find that the most active trading zone takes the price leadership role. The policy implications of our results are twofold. First, the results show the potential for market based solutions to environmental problems such as irrigation water in that the recently created water markets have similar characteristics to more liquid and efficient financial markets. Second, the results show the potential for additional gains from removing trading impediments and increasing trading volumes.

Our results also provide suggestions for future research on the topic of information flows and price formation in water markets. The results on foreign exchange markets (see Menkhoff and Schmeling [7]) show that larger traders convey more information to the market. With information on trade size this matter could also be explored in the context of water markets. This could also be linked to the findings of Wheeler et al. $[14,15]$ on the characteristics of traders who are early adopters of water trading. The interactions of price leadership roles 
of water exchanges with characteristics of traders remains a matter for future research.

\section{References}

[1] Harris, E., The impact of institutional path dependence on water market efficiency in Victoria, Australia. Water Resources Management, forthcoming, 2011.

[2] Brennan, D., Water policy reform in Australia: lessons from the Victorian seasonal water market. Australian Journal of Agricultural and Resource Economics, 50(3), pp.403-423, 2006.

[3] Brennan, D., Missing markets for storage and the potential economic cost of expanding the spatial scope of water trade. Australian Journal of Agricultural and Resource Economics, 52(4), pp. 471-485, 2008.

[4] Brooks, R. and Harris, E., Efficiency gains from water markets: Empirical analysis. Agricultural Water Management, 95(4), pp. 391-399, 2008.

[5] Wheeler, S., Bjornlund, H., Shanahan, M. and Zuo, A., Price elasticity of water allocations demand in the Goulburn-Murray Irrigation District. Australian Journal of Agricultural and Resource Economics, 52(1), pp. 37-55, 2008.

[6] Bjornlund. H., Efficient water market mechanisms to cope with water scarcity. International Journal of Water Resources Development, 19(4), pp. 553-567, 2003.

[7] Menkhoff, L. and Schmeling, M., Whose trades convey information? Evidence from a cross-section of traders. Journal of Financial Markets, 13(1), pp. 101-128, 2010.

[8] Roope, M. and Zurbruegg, R., The intra-day price discovery process between the Singapore Exchange and Taiwan Futures Exchange. Journal of Futures Markets, 22(3), pp. 219-240, 2002.

[9] Hsieh, W., Regulatory changes and information competition: The case of Taiwan index futures. Journal of Futures Markets, 24(4), pp. 399-412, 2004.

[10] Chordia, T. and Swaminathan, B., Trading volume and crossautocorrelations in stock returns. Journal of Finance, 55(2), pp. 913-935, 2000.

[11] Brooks, R., Harris, E. and Joymungul, Y., Market depth in an illiquid market: Applying the VNET concept to Victorian water markets. Applied Economics Letters, 16(13), pp. 1361-1364, 2009.

[12] Brooks, R., Harris, E. and Joymungul, Y., Price clustering in Australian water markets. Applied Economics, forthcoming, 2011.

[13] Levin, A., Lin, C. and Chu, C., Unit root tests in panel data: asymptotic and finite-sample properties. Journal of Econometrics, 108(1), pp. 1-24, 2002.

[14] Wheeler, S., Bjornlund, H., Shanahan, M. and Zuo, A., Who trades water allocations? Evidence of the characteristics of early adopters in the 
Goulburn-Murray Irrigation District, Australia 1998-99. Agricultural Economics, 40(6), pp. 631-643, 2009.

[15] Wheeler, S., Bjornlund, H., Zuo, A. and Shanahan, M., The changing profile of water traders in the Goulburn-Murray Irrigation District, Australia. Agricultural Water Management, 97(9), pp. 1333-1343, 2010. 